\title{
Evaluation of slope stability by finite element method using observed displacement of landslide
}

\author{
Yasuo ISHII · Keiichi OTA · Senro KURAOKA · Ryosuke TSUNAKI
}

Yasuo ISHII

University of Tsukuba (Former Public Works Research Institute),

1-1-1, Tennohdai, Tsukuba, Ibaraki Prefecture, 305-8572, Japan

e-mail: ishii.yasuo.gw@u.tsukuba.ac.jp

Tel: +81-29-853-5878

Fax: +81-29-853-5880

Keiichi OTA, Senro KURAOKA

Nippon Koei Co., Ltd.,

2304, Inarihara, Tsukuba, Ibaraki Prefecture, 300-1259, Japan

Ryosuke TSUNAKI

Sabo Technical Center,

4-8-21, Kudan-minami, Chiyoda-ku, Tokyo, 102-0074, Japan

\begin{abstract}
To monitor land deformation in detail, we ran a large-scale field test in which an artificial landslide was induced by the application of a load to a natural slope. The measured landslide displacement was reproduced numerically through the use of finite element model analysis with a two-dimensional elasto-viscoplastic model. The analysis suggested that the strength of the sliding surface decreased as the landslide mass moved. We propose a simple method for estimating safety factors. The method involves back-calculation of shear strength parameters through reproduction of observed landslide displacements and calculating the ratio of driving
\end{abstract}


force to resisting force acting on the sliding surface as modeled by joint elements. This ratio, the "stability index", shows the same trend as safety factors calculated by a two-dimensional limit equilibrium method and a shear strength reduction method that use back-calculated shear strength parameters estimated from the limit equilibrium state. The results indicate that the stability index may be applicable to the assessment of slope stability.

Keywords: Landslide, Safety Factor, Finite Element Method, Field Test 


\section{Introduction}

Stability analyses and the prevention of landslides on natural slopes in Japan are, in many cases, performed for landslide masses that are found to be unstable owing to weak preexisting sliding surfaces that are formed during past landslide movements. The stability of such landslide masses is conventionally evaluated in terms of safety factors by limit equilibrium methods (see Duncan 1996). However, one of the major difficulties in estimating the safety factor of landslides is due to the uncertainties of the shear strength parameters of natural slopes, which often consist of complex weathered materials.

In Japan, therefore, safety factors of landslides on natural slopes are usually not deterministically predicted from shear strength parameters of the sliding surface as determined by laboratory or in-situ tests. It is the general practice, in many cases, to backcalculate the shear strength parameters of the sliding surface with a safety factor, often assumed to be certain value (e.g., 1.0), based on observation of deformations or movements of landslides. The amount of prevention works needed, such as piling and drainage, are then estimated by calculating the additional resistance force that is needed to increase the safety factor to an acceptable level (NILIM and PWRI 2009).

While the above method is empirically proven to be effective in planning prevention works, the basis for assuming the safety factor is not quantitatively clear. The major interest of our study was to examine a potential method to estimate the strength parameters, and therefore the safety factor, on the basis of the relation between measured displacements and strength parameters of the sliding surface. If the landslide mass is moving along the sliding surface, the measured displacement rates are likely to be higher for weaker sliding surfaces. Therefore, the shear strength parameters and the safety factor may be estimated if a relationship between the displacement rates and the strength parameters can be found.

To study the mechanisms of landslides in more detail and to perform a preliminary study 
to examine the relationships among the measured displacements, the strength of the sliding surface, and the safety factor, we conducted a large-scale field experiment in which we induced a landslide by soil embankment on top of the natural slope from September to December 2000. The size of the landslide was relatively small—60 m long and $50 \mathrm{~m}$ wide— permitting detailed subsurface exploration, including exploratory trenches and a shaft which were excavated in 2001, to reveal the overall geological structure and characteristics of the sliding surface.

The displacement of the landslide mass was monitored by ground extensometers and sensors installed in boreholes. The details of the subsurface exploration and the monitored behaviors are discussed in our previous papers (Ishii et al. 2001; Ishii et al. 2005). Here, we focus on the numerical simulation of the measured displacements, taking into account a sliding failure along a pre-existing sliding surface revealed by the exploration shaft and trenches.

Finite element analysis (FEA) was used to estimate the shear strength of the sliding surface that can reproduce the actual displacement of the landslide mass. We used a twodimensional (2D) finite element model (FEM) — an elasto-viscoplastic constitutive model— to simulate a landslide exhibiting a creep type of steady deformation up to the acceleration mode of deformation. In particular, a joint element model (Goodman 1968) with elasto-viscoplastic constitutive model was developed in this study to simulate the sliding behavior of a landslide mass along the sliding surface. This interface model was developed, since many landslides on natural slopes in Japan form along pre-existing sliding surfaces, which are usually the weakest layer. In addition, we examined methods to estimate safety factors through simulation of the displacement.

The shear strength reduction method (SSRM) is commonly used in obtaining safety factors by FEM (Zienkiewicz et al. 1975; Matsui and San 1992; Ugai and Leshchinsky 1995; 
Dawson et al. 1999; Griffiths and Lane 1999; Cheng et al. 2007; Tsuchiya et al. 2009).

Through iterative computation, the strengths are gradually reduced until a state of nonconvergence is reached. An elasto-viscoplastic simulation could require a significant amount of computation to find the state of non-convergence, since it is difficult to find the limiting strengths that differentiate the displacement rates that reach zero from those that do not reach zero. Hence, a stability index equivalent to the safety factor by the enhanced limit strength method (Fredlund and Scoular 1999) was computed as the ratio of the summed shear force to the summed resisting forces acting on each joint element. Although this ratio is not the same as a safety factor calculated by dividing the given strengths by the strengths at limit equilibrium, the calculation is simple and less time consuming than the SSRM. We evaluated the applicability of the proposed stability index by comparison with safety factors calculated by the Fellenius method, Morgenstern and Price’s (1965) method, and the SSRM using elasto-plastic FEA.

\section{Field loading test}

We conducted the field loading test on a sloping ridge formed in layers of mudstone and tuff of the Neogene period in 2000. The slope had a width of about $50 \mathrm{~m}$ and a length of about 60 m. The monitoring system consisted of ground extensometers (S-1, S-2), a borehole inclinometer (BV-1), a borehole extensometer (BV-7), and groundwater level gauges (W-1, adjacent to BV-1) (Fig. 1). Pipe strain gauges (W-1, BV-9) and a multipoint borehole extensometer (BV-5) were installed to investigate the depth of the sliding surface (Ishii et al. 2001; Ishii et al. 2005).

The test involved initial excavation near the toe of the slope, loading and unloading by deposition and removal of a soil embankment on top of the slope (Figs. 1-4), and continuous monitoring of displacement. A water pit was also excavated in the upper area before the 
embankment work (Fig. 4) in attempt to induce landslide movements by increasing the pore water pressure applied on the sliding surface, but it was not used, since it was obvious that the water could not reach the sliding surface on account of the low soil permeability.

The embankment was formed in increments of 0.5 or $1.0 \mathrm{~m}$ in height by an unmanned backhoe to ensure the safety of the workers. The surface of the embankment at each stage was kept horizontal. Decisions to load or unload the embankment were based on the rates of displacement identified by the ground extensometers. The surface elevation of the embankment was surveyed accurately by theodolite. The initial elevation of the ground crest was $287.0 \mathrm{~m}$. The embankment work was temporarily halted at $+2.0 \mathrm{~m}$ (for 3 days) and +3.5 m (for 1 day) to examine the response of the displacement rates (Fig. 3b). After three stages of embankment works, the final elevation of the embankment was $+4.6 \mathrm{~m}$.

While the soil was embanked on the slope, the ground extensometers recorded cumulative displacement. The displacement decelerated when the deposition of soil was suspended, suggesting that the displacements were due mostly to compressive settlement, and that sliding failure had not yet occurred (Fig. 3a): if the sliding failure had occurred, it is unlikely that the displacement would show clear deceleration.

When the elevation of the embanked soil reached $+4.6 \mathrm{~m}$, the rate of displacement monitored by the ground extensometers increased first at a constant rate and later accelerated. The increase in displacement while the elevation of the embankment remained constant indicates the onset of sliding failure, and the state is equivalent to that of "limit equilibrium". Thus, we assessed the state of limit equilibrium on the basis of changes in displacement rate. We use "limit equilibrium" to describe the state equivalent to the onset of failure that occurred when the elevation of the embankment reached $+4.6 \mathrm{~m}$. Displacement values monitored at S-1 and S-2 were generally similar (Fig. 3a). However, after the cumulative displacement at S-1 exceeded $50 \mathrm{~mm}$, the values of S-1 were larger than those of S-2, 
indicating the displacements at S-1 showed a larger response to the loading. Therefore, the changes in displacement are represented by those at S-1 (Fig. 5).

After the slope reached the limit equilibrium at $+4.6 \mathrm{~m}$, the embanked soil was removed in layers $0.5 \mathrm{~m}$ thick. The displacement rates monitored at S-1 decreased continuously during the removal of the soil (Fig. 5). The rate of displacement decreased sharply when the elevation fell below $+2.5 \mathrm{~m}$ : from $30 \mathrm{~mm} /$ day on 23 November 2000 to $2.68 \mathrm{~mm} /$ day on 26 November 2000 . The rate gradually reduced to $0.0 \mathrm{~mm} /$ day when the elevation of the embankment reached $+2.0 \mathrm{~m}$. Although there was no distinct change in the rate of displacement, which can be related to the transition from the state of sliding failure to stability, these trends imply that the slope became stable when the elevation of the embankment was between $+2.0 \mathrm{~m}$ and $+2.5 \mathrm{~m}$. The elevation that initiated sliding failure $(+4.6 \mathrm{~m})$ was greater than the elevation that halted the sliding movement $(+2.0 \mathrm{~m})$. The fact that the displacement rate did not diminish to a marginal level until the elevation was reduced to about $+2.0 \mathrm{~m}$ implies that the shear strength of the sliding surface was reduced.

The borehole extensometer at BV-7 showed contractive deformation until the embankment reached the maximum height of $+4.6 \mathrm{~m}$ (Fig. 6a). Then it started to show extension of wire. The contractive deformation indicates compressive settlement due to the surcharge, whereas the extension of wire suggests initiation of the sliding failure, which became the dominant component of the deformation.

The distributions of vertical strains at W-1 and BV-9 clearly indicate the sliding behavior of the mass along the sliding surface (Fig. 7). The depth of the sliding surface was around 11 $\mathrm{m}$ at $\mathrm{W}-1$ and $2 \mathrm{~m}$ at BV-9. These results suggest that most of the displacement was due to the sliding failure when the elevation of the embankment reached $+4.6 \mathrm{~m}$.

The slope consisted of alternate layers of tuff and mudstone dipping in opposite gradient to the angle of the sliding surface (Fig. 4). Surveys inside the later-dug exploration shaft and 
trenches in 2001 showed the formation of the sliding surface; that inside the shaft was formed mostly between a gray tuff clay layer 10-20 cm thick and an overlying brown clay layer 10$20 \mathrm{~cm}$ thick (Fig. 8). Clear scars were visible on the sliding surface. A Riedel shear structure was also observed in the gray tuff clay that spread beneath the sliding surface. These clues suggest that the sliding surface had been formed during past movements.

Almost no ground water was observed above the sliding surface during the excavation of the shaft, indicating that ground water had little effect on the sliding failure during the loading.

\section{Numerical simulation}

\section{Measured displacements for the simulation}

A preliminary FEA with the elasto-viscoplastic model of the sliding surface examined the correlation of the shear strengths with the measured displacement rate indicative of the sliding failure. This preliminary analysis used a 2D model. The 2D finite element mesh was generated along a cross-section parallel to the direction of the slide over the largest crosssectional area of the landslide (Fig. 4).

The displacements measured by the ground extensometers S-1 and S-2 were the only data that could be compared with the FEA, since the results from the sensors installed in the boreholes did not directly show sliding displacements. After the field test, we retrieved the guide pipe of the inclinometer (BV-1) from inside the exploratory shaft in 2001. The bend in the pipe suggested that the landslide mass slid $\sim 20 \mathrm{~cm}$ along the sliding surface (Fig. 9).

First, we compared the simulated displacements with the displacement at S-1, which indicated mostly sliding behavior rather than compressive settlement. However, S-1 was not located on the cross-section of the 2D FEM model. Therefore, we used the displacement of the node near the intersection of the borehole (BV-1) and the sliding surface, because the 
displacement of the bent guide pipe was close to that recorded at S-1.

We also compared displacement at S-2 with the simulated displacement. One end of the wire at S-2 was attached to a dowel fixed to the stable ground, and the other end was attached to a dowel fixed at near the edge of the moving landslide. The measured displacement of S-2, therefore, indicated the displacement between the two dowels. We calculated the relative displacements of the two nodes of the elements near S-2 and compared the values with the measured displacements.

\section{Loading and unloading}

The loading and unloading processes of the FEA were configured to simulate the major trends of the displacement rates at S-1 (Fig. 5). In view of the trends of the displacement rates and loading conditions shown in Fig. 5, we divided the loading and unloading procedures into 5 stages. In loading stage 1 (6-13 Nov. 2000), the displacement showed an initial small acceleration and then stopped. In loading stage 2 (13-16 Nov. 2000), the displacement rate accelerated to 9.84 and then to $15.00 \mathrm{~mm} /$ day and then decelerated to $5.58 \mathrm{~mm} /$ day. In loading stage 3 (16-23 Nov. 2000), the displacement increased markedly to $30.00 \mathrm{~mm} /$ day. In unloading stage 1 (23-24 Nov. 2000), the displacement started decelerating. In unloading stage 2 (24-29 Nov. 2000), the displacement further decelerated to near zero.

We matched the FEA to these five stages (Table 1). It was simplified by assuming that the embankment was raised and lowered to the three elevations shown in Fig. 5c with the solid blue line. Because the displacement rate continuously decreased during the removal of soil, we focused on reproducing the accelerating displacement. In practice, soil was gradually embanked, but in the analysis, the load was assumed to have acted suddenly at the start of each loading stage (1-3).

The shear strength parameters were varied so as to reproduce the observed displacement values (to the nearest $10 \mathrm{~mm}$ ). Although the values of shear strength parameters might be 
non-uniform, the average value at the sliding surface was used in the FEA. We assumed that the landslide moved uniformly along the sliding surface.

\section{Numerical simulation}

\section{Numerical model}

We simulated the measured displacements of the landslide to see whether the model could estimate the shear strength of the sliding surface. Although the measured displacement was a result of the complex combination of compression, expansion, and sliding of the landslide mass, our main interest was to simulate the displacement induced by sliding along the sliding surface, which our measurements and observations suggested was the dominant component of the displacement. First, the geological strata in the exploration shaft clearly revealed a preexisting sliding surface (Fig. 8). Second, the distribution of strains measured by pipe strain gauges $\mathrm{W}-1$ and BV-9 show discontinuous movement across the sliding surface (Fig. 7). Hence, the sliding surface was modeled as the only zone that can undergo shear failure, and the landslide mass, embanked soil, and bedrock below the sliding surface were modeled as an elastic material.

The sliding surface was modeled with joint elements (Goodman et al. 1968) with an elasto-viscoplastic constitutive equation. The model was based on the models of Owen and Hinton (1980) and Sekiguchi et al. (1990). The constitutive model is expressed as follows:

$$
\left\{\not \&_{v p}\right\}=\gamma\langle\Phi(x)\rangle \frac{\partial Q}{\partial \sigma}
$$

where $i_{v p}$ is the rate of viscoplastic relative displacement between two nodal points facing each other across the sliding surface, $\gamma$ is the fluidity parameter, $\sigma$ is stress, $Q$ is the plastic potential, and $\Phi(x)$ is a positive, monotonically increasing function for $x>0$. The notation $<>$ indicates: 


$$
\begin{gathered}
\langle\Phi(x)\rangle=\Phi(x)(\text { for } x>0) \text { and } \\
\langle\Phi(x)\rangle=0(\text { for } x<0) .
\end{gathered}
$$

In this analysis, viscoplastic relative displacement is induced when shear failure occurs according to the Mohr-Coulomb criterion. Hence, $x$ must be $>0$ when the shear stresses exceed the shear strength. In this model, $x$ was set as:

$$
x=\frac{F}{F_{0}}
$$

where $F$ is the Mohr-Coulomb yield function and $F_{0}$ is expressed as a function of strength parameters so that $x$ becomes non-dimensional. The function $\Phi(x)$ followed one of the common formulae expressed by Owen and Hinton (1980):

$$
\Phi(x)=\frac{F}{F_{0}}(x>0)
$$

$Q$ and $F$ are defined as:

$$
\begin{gathered}
Q=\sqrt{\tau_{r s}{ }^{2}+\tau_{s r}{ }^{2}} \\
F=\sqrt{{\tau_{r s}{ }^{2}+\tau_{s r}{ }^{2}}^{2}}+\sigma_{n} \cdot \tan \phi-c
\end{gathered}
$$

In this preliminary study, $F_{0}$ is expressed as

$$
F_{0}=c \cdot \tan \phi
$$

which is a slightly modified version of the original formula shown as $F_{0}=c \cdot \cos \phi$ by Owen and Hinton (1980), since $\tan \phi$ indicates the coefficient of friction; $\tau_{r s}$ and $\tau_{s r}$ are shear stresses at the joint element surfaces, $\sigma_{n}$ is the vertical stress acting on the joint element surface (negative compression), $c$ is cohesion, and $\phi$ is the internal friction angle.

The model consists of 686 elements and 1444 nodal points (Fig. 10). 


\section{Physical property values of the simulation}

The FEM was kept simple, consisting of landslide mass, sliding surface, bedrock, and embankment (Fig. 10). Although a water pit is indicated in Fig. 10, the properties were kept same as those of the landslide mass in order to simplify the model. The strata within the landslide mass and the bedrock were not modeled in detail for two reasons. First, we emphasized modeling the sliding behavior along the sliding surface, rather than analyzing the compressive or contractive deformation of the landslide mass induced by the embankment load. Second, in using an elasto-viscoplastic interface model for the first time to examine the correlations between the strengths and displacement rates associated with the sliding, we thought it rational not to assess the properties and behaviors of internal strata, which are difficult to characterize quantitatively owing to limitations in our investigation methods.

The unit weight of the landslide mass was determined from undisturbed samples. The unit weight of the embankment was obtained from the dimensions and weight of the transported soil (Table 2). The modulus of deformation of the landslide mass and that of the bedrock were based on the results of a pressure meter test in a borehole. Values of the modulus of deformation (Table 2), obtained from the pressure meter tests, are shown separately for the layers classified as CL and those classified as D (Japanese Geotechnical Society 2004). The values of CL class fell within the range of about 10000 to $120000 \mathrm{kN} / \mathrm{m}^{2}$, and those of D class within the range of about 10000 to $40000 \mathrm{kN} / \mathrm{m}^{2}$ (Fig. 11). The landslide mass consisted of alternating layers of tuff and mudstone. Because it consisted mainly of tuff in the exploration shaft, the modulus of deformation was set at $11600 \mathrm{kN} / \mathrm{m}^{2}$, which was the mean value of the tuff classified as D. The modulus of deformation of the bedrock was set at $65000 \mathrm{kN} / \mathrm{m}^{2}$, which is roughly the intermediate value for rock mass classified as CL.

The Poisson ratio of the landslide mass was set to 0.4 (Table 2), which is in the lower 
range of the values given for a clay (Hunt 1984), since the landslide mass was relatively soft, as suggested by $\mathrm{N}$-values ranging between 1 and 20. The Poisson ratio of the embanked soil and bedrock were also set to 0.4 .

The normal and shear spring constants of the joint element were set at $5000 \mathrm{kN} / \mathrm{m}^{3}$, which is within the lower range of the shear stiffness values for rock joints with clay filling given by Barton et al. (1985). Although no shear tests of the sliding surface were performed to estimate the spring constants, the effects of spring constants on displacement due to shear failure are small compared with the effects of shear strength parameters (Ishii et al. 2006).

Additionally, a fluidity parameter $(\gamma)$ is required for the elasto-viscoplastic joint model. The fluidity parameter, as defined in the previous section, affects the initial displacement rates of the joint elements that have just yielded. As can be seen in Equation (1), this parameter does not affect the displacement unless the joint element yields. No specific methods have been developed to determine $\gamma$ of the joint element. In this study, $\gamma$ was determined through the simulation of the first loading stage. As no significant continuous sliding failure occurred during the first stage of loading, the simulated displacement rates were more affected by $\gamma$. Hence, we selected the value of $\gamma$ such that the initial displacement rate of the first stage of loading was reasonably close to the measured rate. The value was determined to be 0.025 day $^{-1}$, which is the value used in the simulation presented by Ishii et al. (2006). The measured displacement rates in the second and third loading stages were reproduced by varying the strengths, while $\gamma$ was fixed at 0.025 day $^{-1}$. The displacement rates of the second and third stages of loading are largely due to sliding failure, which is controlled by the strength parameters rather than $\gamma$. 


\section{Results of numerical simulation}

\section{Simulation}

First, the initial stress state was generated by the application of gravity. Second, the initial excavation near the toe of the slope was simulated. Third, loading and unloading were simulated in five stages. The model focused on simulating the displacement associated with the sliding behavior of the landslide mass during the five stages. Up to the initial excavation of the slope, the shear strength of the sliding surface was set high to prevent sliding, since no significant deformation of the landslide was observed until the application of the embankment load.

We used trial and error to find the cohesion values and the internal friction angles that best reproduced the measured displacement. A sensitivity analysis of loading stage 1 was performed with various combinations of cohesion values from 9.0 to $30.0 \mathrm{kN} / \mathrm{m}^{2}$ and internal friction angles from $10.0^{\circ}$ to $20.0^{\circ}$. These ranges were selected with reference to the shear strengths obtained from laboratory tests of samples containing clays of the sliding surfaces (Table 3).

The cohesion corresponding to the fully softened shear strength cohesion varied between 6.8 and $14.0 \mathrm{kN} / \mathrm{m}^{2}$, and the internal friction angle varied between $11.9^{\circ}$ and $25.2^{\circ}$ (Table 3). The cohesion corresponding to the residual strength varied between 2.7 and $23.4 \mathrm{kN} / \mathrm{m}^{2}$, and the internal friction angle varied between $1.9^{\circ}$ and $13.2^{\circ}$. Following the sensitivity analysis of loading stages $1-3$, we fixed the internal friction angle at $14.0^{\circ}$ and the estimated cohesion to be within the range of 5.0 to $9.1 \mathrm{kN} / \mathrm{m}^{2}$. Although the strengths obtained from the laboratory tests show scatter, these values of cohesion and internal friction angle fall within the range between the fully softened shear strength and the residual shear strength, and are consistent with the results of the soil test.

During loading stage 1 , the cumulative displacement become close to the measured value 
(S-1), $20 \mathrm{~mm}$, when cohesion was $9.1 \mathrm{kN} / \mathrm{m}^{2}$ and the internal friction angle was $14.0^{\circ}$ (Fig. 12). The displacement rate was reduced to almost zero in about 5 days. During loading stage 2, the cumulative displacement became about $60 \mathrm{~mm}$ under the same conditions as in loading stage 1 . Thus, the shear strength parameters determined in loading stage 1 were adequate. During loading stage 3, the increase in displacement could not be reproduced when the same shear strength parameters were used. Thus, the cohesion determined in loading stages 1 and 2 was gradually reduced after the application of the soil embankment during loading stage 3 on the assumption that softening reduced the strength. The simulated displacement indicated acceleration during loading stage 3 when cohesion was reduced from 9.1 to $5.0 \mathrm{kN} / \mathrm{m}^{2}$ at a rate of $0.68 \mathrm{kN} / \mathrm{m}^{2} /$ day (Fig. 13). In this simulation, the cohesion was reduced as a function of time, since the constitutive equation did not have the capability to simulate softening behavior as a function of strain or displacement. The model needs to be modified to incorporate softening behavior in the future. The cumulative displacement was about $200 \mathrm{~mm}$, reasonably close to the measured displacement at S-1. The measured and simulated displacements at S-2 also show reasonable agreement (Fig. 13). Hence, the FEM model based on the elastoviscoplastic constitutive model for the joint elements was appropriate for simulating the movements of the slope, including acceleration.

The internal friction angle was also reduced to show the effects on displacement while the cohesion remained constant. The change in the displacement was larger when the internal friction angle was changed by $0.1^{\circ}$ than when the cohesion was changed by $0.1 \mathrm{kN} / \mathrm{m}^{2}$. The results imply that the internal friction angle needs to be adjusted with a precision of $\sim 0.01^{\circ}$. However, estimating the internal friction angle with such precision is not practical, so we made no further attempt to simulate the displacement by adjusting the angle. Therefore, it has a possibility of another suitable combination beside the back-calculated value.

Analyses of unloading stages 1 and 2 using the reduced cohesion to simulate the 
accelerating trend of displacement of S-1 observed in loading stage 3 showed that the simulated displacement kept increasing even after the unloading, whereas the measured displacement stopped increasing 5 days after unloading stage 1 . Thus, the amount of reduction in strength during the simulation of loading stage 3 may have been too large. We reduced the rate of decrease in cohesion during loading stage 3 to reproduce the trend of displacement observed during unloading. When the cohesion was reduced from 9.1 to 7.0 $\mathrm{kN} / \mathrm{m}^{2}$, the displacement stopped increasing after unloading (blue line in Fig. 12). However, the simulated displacement up to loading stage 3 is small compared with the measured displacement. Furthermore, the measured displacement gradually decelerated, whereas the simulated displacement stopped suddenly with a terminal value smaller than the measured value.

Although it might have been possible to adjust the strength in more detail to obtain better agreement between the simulated and measured displacements throughout the five loading stages, no further attempt was made, as the FEM cannot incorporate all the factors affecting the movement of the landslide. First, FEA uses a 2D model, whereas the actual landslide mass and the sliding surface have 3D geometries. Second, the modeled sliding surface was assumed to have uniform strength properties, whereas the actual sliding surface is expected to be nonuniform. Third, the landslide mass was modeled as a uniform elastic material, whereas the actual landslide mass is likely non-uniform and must have undergone plastic deformation, even though the measured displacements are mostly attributable to the sliding behavior.

These results show that it may be possible to estimate the strength of the sliding surface through simulations of the measured displacement. As the strength of the sliding surface needs to be reduced to reproduce the acceleration mode, the sliding surface may have softened. 


\section{Safety factors based on simulation of monitored displacement data}

\section{Objectives and scope of study}

This section concerns methods for calculating safety factors from the strengths estimated by the simulation. Safety factors may be calculated by limit equilibrium methods, using the strengths obtained by numerical simulations. However, the strengths that are back-calculated by one method are not necessarily applicable in expressing the state of stability determined by other methods; e.g., the strength back-calculated by Morgenstern and Price’s method may give a safety factor of $<1.0$, whereas the same strengths may yield a safety factor of $>1.0$ if computed by FEM. This discrepancy is due to the differences in the assumptions made in deriving the governing equations or the constitutive equations, and to differences in the parameters that are used in those equations. Therefore, we used FEM to obtain the safety factors in order to avoid such differences.

It is important to be aware of the assumptions and theoretical background that lead to these differences. However, assessing the reasons for differences in safety factors resulting from different methods is beyond the scope of this paper. It is also likely that the differences in the safety factors resulting from conventional methods are less significant than the margin of error of safety factors due to uncertainties associated with the inhomogeneity, geometries, depths, and thicknesses of the sliding surfaces.

We compared the safety factors obtained from the FEA with those obtained by other methods so as to appraise the simplified method for obtaining the safety factor from the stresses of joint elements. However, detailed studies were not performed for the reasons stated above. 


\section{The proposed method}

As mentioned in the Introduction, the SSRM is commonly used in obtaining safety factors with FEM. Elasto-plastic models use iterative computations performed with SSRM. The resulting safety factor is the same as the safety factor defined as the ratio of the given shear strengths to the shear strengths at limit equilibrium. Elasto-viscoplastic simulations, however, can need significant amounts of iterative computations to find the state of non-convergence, since it is difficult to find the limiting strengths that differentiate the displacement rates that reach zero from those that do not reach zero.

A less time consuming method to obtain the safety factors may be to calculate the ratio of the summed shear forces to the summed resisting forces acting on each joint element. This “enhanced limit strength method” was introduced for use with elastic or elasto-plastic FEA; i.e., the ratio of the resisting force to the driving force is calculated from the stresses computed by FEA (Fredlund and Scoular 1999).

Here, we refer to the safety factors obtained from the enhanced limit strength method as the "stability index". We use this term in order to differentiate the safety factor obtained by SSRM from that obtained by the enhanced limit strength method. For 2D FEA, the stability index, $S I$, is calculated as:

$$
S I=\frac{\sum(\sigma \cdot \tan \phi+c) \cdot \Delta l}{\sum \tau \cdot \Delta l}
$$

where $\sigma$ is the normal stress acting on the joint element of the sliding surface, $\phi$ is the internal friction angle of the sliding surface, $c$ is the cohesion of the sliding surface, $\tau$ is the shearing stress acting on the joint element of the sliding surface, and $\Delta l$ is the length of the joint element. SI is obtained by scalar summation of the shear forces, and does not take into account the directions of the shear forces. 


\section{Comparison of SI with safety factors obtained by other methods}

To examine whether $S I$ is adequate at expressing the state of stability, we compared SI of the simulated loading state with safety factors calculated by the Fellenius method, Morgenstern and Price’s method, and SSRM using elasto-plastic FEA.

While it was possible to compare the safety factors using the same shear strengths obtained from the simulation, our interest was to compare the SI with the safety factors obtained by conventional procedures used in designing prevention works in Japan, where shear strengths are back-calculated from an assumed safety factor. So we back-calculated the shear strengths for the three methods using the same safety factor, 1.0, corresponding to the onset of distinct sliding failure. SI, on the other hand, is based on the shear strengths obtained from the simulations. Consequently, the shear strengths back-calculated from the same reference safety factor were different for each method.

The common reference safety factor for the three methods was chosen to be 1.0, which corresponds to the onset of distinct sliding failure when the embankment reached $+4.6 \mathrm{~m}$ during loading stage 3. The internal friction angles were back-calculated, while the cohesion was assumed to be $10.0 \mathrm{kN} / \mathrm{m}^{2}$, which is close to the average value obtained by laboratory tests (Table 3). The back-calculated internal friction angles were $14.89^{\circ}$ for the Fellenius method, $14.23^{\circ}$ for Morgenstern and Price’s method, and $13.64^{\circ}$ for SSRM.

The safety factors, and SI in particular, decreased as loading progressed (Fig. 14, Table 4). The differences among methods were small at loading stage 3, clearly because the state of stability is assumed to be near the limit equilibrium in all methods.

The SSRM safety factor and SI were close until the beginning of loading stage 3, and then diverged towards the end of loading stage 3 . The divergence is due to the fact that $S I$ is calculated from the stresses obtained from the simulations, and the cohesion is gradually reduced to reproduce the accelerating trends of the observed displacements. 
The differences between the values obtained from FEA and the two limit equilibrium methods tended to be large before the beginning of each loading stage, and then diminished: the difference was approximately 0.04 before loading started (Fig. 14, Table 4). The differences may be attributable to the differences in the distribution of the shear and normal forces computed by the different methods.

SI was close to the safety factors obtained by SSRM from loading stage 1 up to the beginning of loading stage 3 . This result implies that it may be possible to assess the stability of a slope in terms of SI, without assuming safety factors, through simulations of displacements if the sliding surface is known. However, the applicability of SI may depend on the shape and gradient of the sliding surface, since it does not account for the difference in the direction of the shear forces acting on the sliding surface. Further studies are required to assess the applicability of SI for landslides having sliding surfaces with different geometries.

\section{Trends of SI with respect to the displacement rate}

The values of SI during loading stage 3 ranged between 1.00 and 0.96 , corresponding to simulated displacement rates at BV-1 and S-2 ranging between approximately 3 and 35 $\mathrm{mm} /$ day (Fig. 15). The trends at the two points showed no notable differences. Although the values of SI against the measured displacements are more scattered, the correlations are similar to those of the simulated displacement rates (Fig. 16). These results suggest that $S I$ obtained by simulation may provide a quantitative basis for estimating safety factors from monitored displacements. However, these findings are limited to the landslide studied in this research. Further studies are required to validate and refine the models in order to estimate safety factors of active landslides with pre-existing sliding surfaces. 


\section{Conclusions}

This paper describes the applicability of a 2D elasto-viscoplastic finite element model of joint elements for simulating the movement of a landslide. A simple method for estimating a safety factor, SI, was tested by finite element analysis without the assumption of a safety factor. The following conclusions are drawn:

1) The elasto-viscoplastic constitutive model of joint elements can simulate the movements of the slope, including acceleration.

2) It may be possible to estimate the strength parameters of the sliding surface through simulations of measured displacement.

3) The accelerating behavior of displacement may be due to softening of the sliding surface.

4) SI showed the same trend as the safety factors calculated by Fellenius methods, Morgenstern and Price’s method, and SSRM using elasto-plastic FEA, but without assumptions about safety factors in a specific state. SI may be applicable to the assessment slope stability if the sliding surface is known.

The proposed method for assessing the stability of a slope by SI is a preliminary attempt, and its reliability is limited. Hence, further studies are required to assess the applicability of $S I$ for landslides having sliding surfaces with different geometries. 


\section{References}

Barton N., Bandis S. and Bakhtar K. (1985) Strength deformation and conductivity coupling of rock joints. International Journal of Rock Mechanics and Mining Sciences \& Geomechanics Abstracts 22(3): 121-140

Cheng Y. M., Lansivaara T. and Wei W. B. (2007) Two-dimensional slope stability analysis by limit equilibrium and strength reduction methods. Computers and Geotechnics 34(3): $137-150$

Dawson E. M., Roth W. H. and Drescher A. (1999) Slope stability analysis by strength reduction. Geotechnique 49(6): 835-840

Duncan J. M. (1996) Soil Slope stability Analysis. In: Turner AK, Schuster RL (eds) Landslides Investigation and Mitigation. Special Report 247, Transportation Research Board, National Research Council, Washington DC, pp 337-371

Fredlund D. G. and Scoular R. E. G. (1999) Using limit equilibrium concepts in finite element slope stability analysis. In: Yagi N., Yamagami T., Jiang J.C. (eds) Slope Stability Engineering. A. A. Balkema, Rotterdam, pp 31-47

Goodman R. E., Taylor R. L. and Brekke T. L. (1968) A model for the mechanics of jointed rock. Journal of the Soil Mechanics and Foundations Division 94(SM3): 637-659

Griffiths D. V. and Lane P. A. (1999) Slope stability analysis by finite elements. Geotechnique 49(3): 387-403

Hunt R.E. (1984) Geotechnical Engineering Investigation Handbook. McGraw-Hill, New York, p 206

Ishii Y., Fujisawa K., Nakashima Y. and Kuraoka S. (2006) Finite element analysis of restraint piles and landslide triggered by groundwater. Journal of the Japan Landslide Society 43(2): 51-59 (in Japanese)

Ishii Y., Tsunaki R., Asano H. and Sugimoto H. (2001) Characteristics of landslide movement 
during filling observed through field loading test. Civil Engineering Journal 43(11): 3237 (in Japanese)

Ishii Y., Tsunaki R., Sugimoto H., Asano H. and Osanai, N. (2005) Effect of analysis method for safety factor of landslide obtained through field loading test. Journal of the Japan Landslide Society 41(6): 595-606 (in Japanese)

Japanese Geotechnical Society (2004) Method for engineering classification of rock mass (JGS: 3811-2004). Japanese Geotechnical Society, Tokyo, pp 39-41

Morgenstern N. R. and Price V. E. (1965) The analysis of the stability of general sliding surfaces. Geotechnique 15(1): 79-93

NILIM (National Institute for Land Infrastructure Management) and PWRI (Public Works Research Institute) (2009) Ministry of Land, Infrastructure, Transport and Tourism Technical Criteria for River Works: Practical Guide for Planning. Technical Note of NILIM No. 519 and PWRI No. 4132, p 196

Owen J. and Hinton E. (1980) Finite Elements Plasticity; Theory \& Practice. Pineridge Press, Swansea, pp 272-318

Sekiguchi K., Rowe R.K. and Lo K.Y. (1990) Time step s election for 6 noded non-linear joint element in elasto-viscoplasticity analyses. Computers and Geotechnics 10(1): 33-58

Tsuchiya S., Sasahara K., Shuin S. and Ozono S. (2009) The large-scale landslide on the flank of caldera in South Sulawesi, Indonesia. Landslides 6(1): 83-88

Ugai K. and Leshchinsky D. (1995) Three-dimensional limit equilibrium and finite element analysis: a comparison of results. Soils and Foundations 35(4): 1-7

Matsui T. and San K. C. (1992) Finite element slope stability analysis by shear strength reduction technique. Soils and Foundations 32(1): 59-70

Zienkiewicz O. C., Humpheerson C. and Lewis R. W. (1975) Associated and non-associated visco-plasticity and plasticity in soil mechanics. Geotechnique 25(4): 671-689 
Table 1 Target displacement in each loading stage for FEM.

\begin{tabular}{c|c|c|c|l}
\hline Loading/unloading stage & Period & $\begin{array}{c}\text { Cumulative } \\
\text { displacement } \\
(\mathrm{mm})\end{array}$ & $\begin{array}{c}\text { Target value to } \\
\text { reproduce } \\
\text { (mm) }\end{array}$ & Remark \\
\hline Loading stage 1 & 6-13 Nov., 7 days & 24.98 & 20 & Rate became almost zero \\
\hline Loading stage 2 & 13-16 Nov., 3 days & 55.40 & 60 & Rate became 5.58 mm/day \\
\hline Loading stage 3 & 16-23 Nov., 7 days & 181.42 & 180 & Rate accelerated to >15.00 mm/day \\
\hline Unloading stage 1 & 23-24 Nov., 1 day & 200.70 & 200 & Rate decelerated \\
\hline Unloading stage 2 & 24-29 Nov., 5 days & 213.66 & 210 & Rate became almost zero \\
\hline
\end{tabular}

Table 2 Analytical parameters used in FEM analysis.

\begin{tabular}{|c|c|c|c|c|c|}
\hline & $\begin{array}{l}\text { Type of } \\
\text { element }\end{array}$ & Constitutive law & Unit weight & $\begin{array}{l}\text { Modulus of } \\
\text { deformation }\end{array}$ & Poisson ratio \\
\hline Embanked soil & solid & Elastic body & $16.3 \mathrm{kN} / \mathrm{m}^{3}$ & $11600 \mathrm{kN} / \mathrm{m}^{2}$ & 0.4 \\
\hline Landslide mass & solid & Elastic body & $17.7 \mathrm{kN} / \mathrm{m}^{3}$ & $11600 \mathrm{kN} / \mathrm{m}^{2}$ & 0.4 \\
\hline Sliding surface & joint & Elasto-viscoplastic body & $17.7 \mathrm{kN} / \mathrm{m}^{3}$ & - & - \\
\hline Bedrock & solid & Elastic body & $20.0 \mathrm{kN} / \mathrm{m}^{3}$ & $65000 \mathrm{kN} / \mathrm{m}^{2}$ & 0.4 \\
\hline
\end{tabular}


Table 3 Results of shear tests of clays from the sliding surface.

\begin{tabular}{|c|c|c|c|c|c|c|}
\hline \multirow[b]{2}{*}{$\begin{array}{l}\text { Sampling } \\
\text { point }\end{array}$} & \multirow[b]{2}{*}{ Color of sample } & \multirow[b]{2}{*}{ Test } & \multirow[b]{2}{*}{$\begin{array}{c}\text { Sample } \\
\text { condition }\end{array}$} & \multicolumn{3}{|c|}{ Shear strength parameter } \\
\hline & & & & Strength & $\begin{array}{c}\text { Cohesion } \\
\left(\mathrm{kN} / \mathrm{m}^{2}\right)\end{array}$ & $\begin{array}{l}\text { Internal friction } \\
\text { angle }\left({ }^{\circ}\right)\end{array}$ \\
\hline \multirow{2}{*}{$\begin{array}{l}\text { Cut slope } \\
\text { on toe }\end{array}$} & \multirow{2}{*}{ Gray } & \multirow{2}{*}{ Ring shear } & \multirow{2}{*}{ Disturbed } & Fully softened & 14.0 & 21.4 \\
\hline & & & & Residual & 5.0 & 8.9 \\
\hline \multirow{8}{*}{ Shaft } & \multirow{2}{*}{ Brown and gray } & \multirow{2}{*}{ Direct shear } & \multirow{2}{*}{ Undisturbed } & Peak & 51.8 & 9.3 \\
\hline & & & & Residual & 12.8 & 10.1 \\
\hline & \multirow{2}{*}{ Gray } & \multirow{2}{*}{ Ring shear } & \multirow{2}{*}{ Disturbed } & Fully softened & 9.0 & 24.3 \\
\hline & & & & Residual & 2.7 & 9.9 \\
\hline & \multirow{2}{*}{ Gray } & \multirow{2}{*}{ Direct shear } & \multirow{2}{*}{ Disturbed } & Fully softened & 10.2 & 25.2 \\
\hline & & & & Residual & 5.5 & 8.9 \\
\hline & \multirow{2}{*}{ Gray } & \multirow{2}{*}{ Ring shear } & \multirow{2}{*}{ Disturbed } & Fully softened & 12.8 & 22.1 \\
\hline & & & & Residual & 7.5 & 13.2 \\
\hline \multirow{4}{*}{$\begin{array}{l}\text { Trench } \\
\text { No. } 1\end{array}$} & \multirow{2}{*}{ Brown and gray } & \multirow{2}{*}{ Direct shear } & \multirow{2}{*}{ Undisturbed } & Peak & 44.7 & 17.0 \\
\hline & & & & Residual & 23.4 & 9.6 \\
\hline & \multirow{2}{*}{ Gray } & \multirow{2}{*}{ Ring shear } & \multirow{2}{*}{ Disturbed } & Fully softened & 9.7 & 21.0 \\
\hline & & & & Residual & 3.7 & 9.4 \\
\hline \multirow{2}{*}{$\begin{array}{l}\text { Trench } \\
\text { No. } 2\end{array}$} & \multirow{2}{*}{ Brown and gray } & \multirow{2}{*}{ Ring shear } & \multirow{2}{*}{ Disturbed } & Fully softened & 6.8 & 11.9 \\
\hline & & & & Residual & 5.5 & 1.9 \\
\hline
\end{tabular}


Table 4 Safety factors calculated by different methods.

\begin{tabular}{c|c|c|c|c|c|c}
\hline \multirow{2}{*}{$\begin{array}{c}\text { Loading } \\
\text { stage }\end{array}$} & \multirow{2}{*}{ Date } & Analysis method & $\begin{array}{c}\text { Fellenius } \\
\text { method }\end{array}$ & $\begin{array}{c}\text { Morgenstern- } \\
\text { Price's method }\end{array}$ & SSRM & SI \\
\cline { 3 - 7 } & & Cohesion $\left(\mathrm{kN} / \mathrm{m}^{2}\right)$ & 10.0 & 10.0 & 10.0 & $5.0-9.1$ \\
\cline { 3 - 7 } & Nov. 4 & & 14.89 & 14.23 & 13.64 & 14.0 \\
\hline \multirow{2}{*}{1} & Nov. 9 & Embankment height $2.0 \mathrm{~m}$ & 1.028 & 1.029 & 1.020 & 1.012 \\
\hline \multirow{2}{*}{2} & Nov. 13 & $3.0 \mathrm{~m}$ & 1.013 & 1.014 & - & - \\
\hline \multirow{2}{*}{3} & Nov. 14 & $3.5 \mathrm{~m}$ & 1.008 & 1.008 & 1.010 & 0.999 \\
\hline & Nov. 16 & $4.0 \mathrm{~m}$ & 1.003 & 1.003 & - & - \\
\hline & Nov. 17 & $4.6 \mathrm{~m}$ & 1.000 & 1.000 & 1.000 & 0.996 \\
\hline & Nov. 18 & $4.6 \mathrm{~m}$ & 1.000 & 1.000 & - & 0.987 \\
\hline & Nov. 19 & $4.6 \mathrm{~m}$ & 1.000 & 1.000 & - & 0.979 \\
\hline & Nov. 20 & $4.6 \mathrm{~m}$ & 1.000 & 1.000 & - & 0.972 \\
\hline
\end{tabular}




\section{Figure captions}

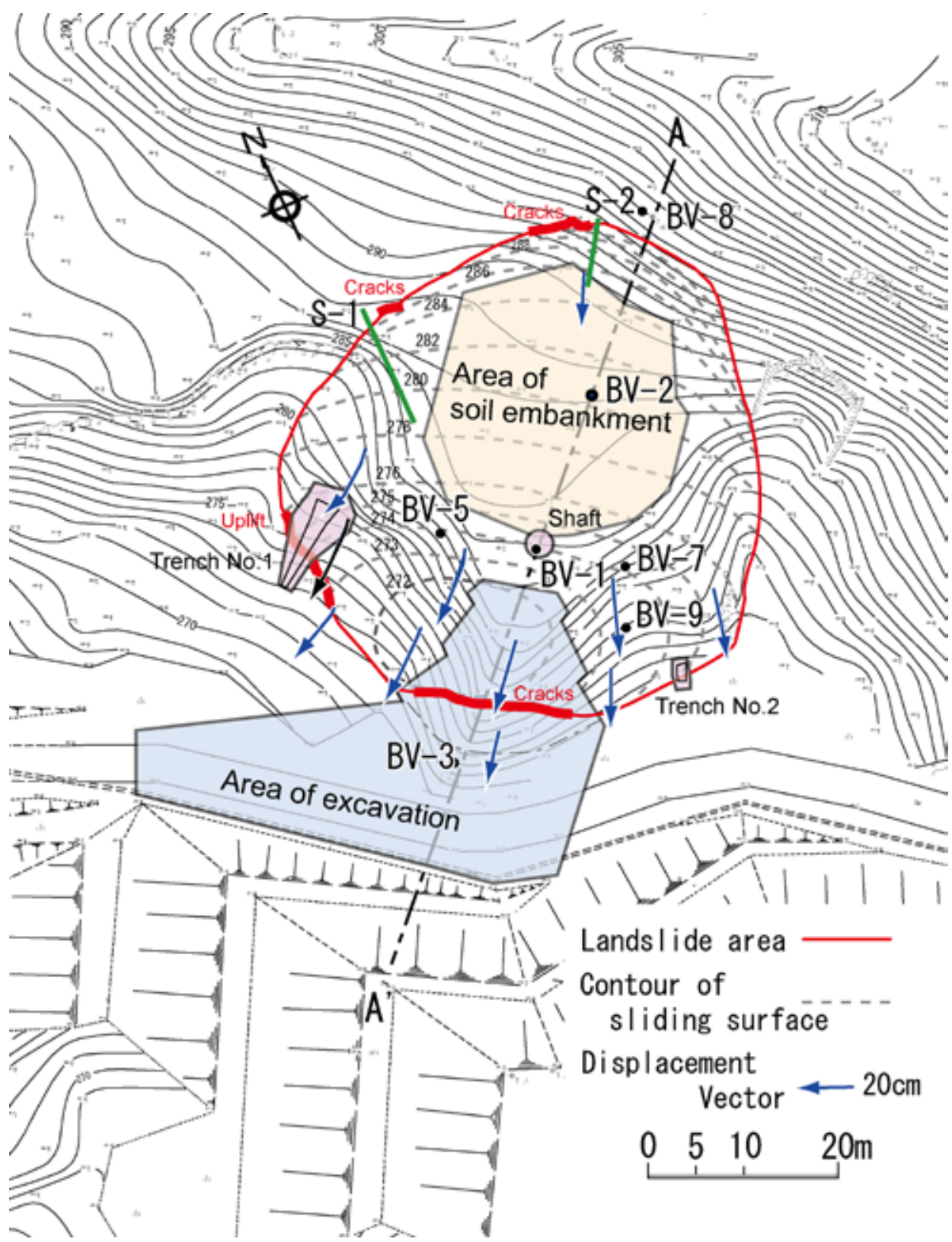

Fig. 1 Topographic map of field loading test site. The area delineated in red identifies the landslide body, which shows surface deformation by cracks and uplift on the margin (thick red lines). Green lines, ground extensometers. Black circles, other monitoring equipment. Shaded orange area, soil embankment. Shaded blue area, excavated area before deposition of soil on top. Shaded violet area, exploration shaft and two trenches. Blue arrows, displacement vector from 24 October to 11 December 2000. 


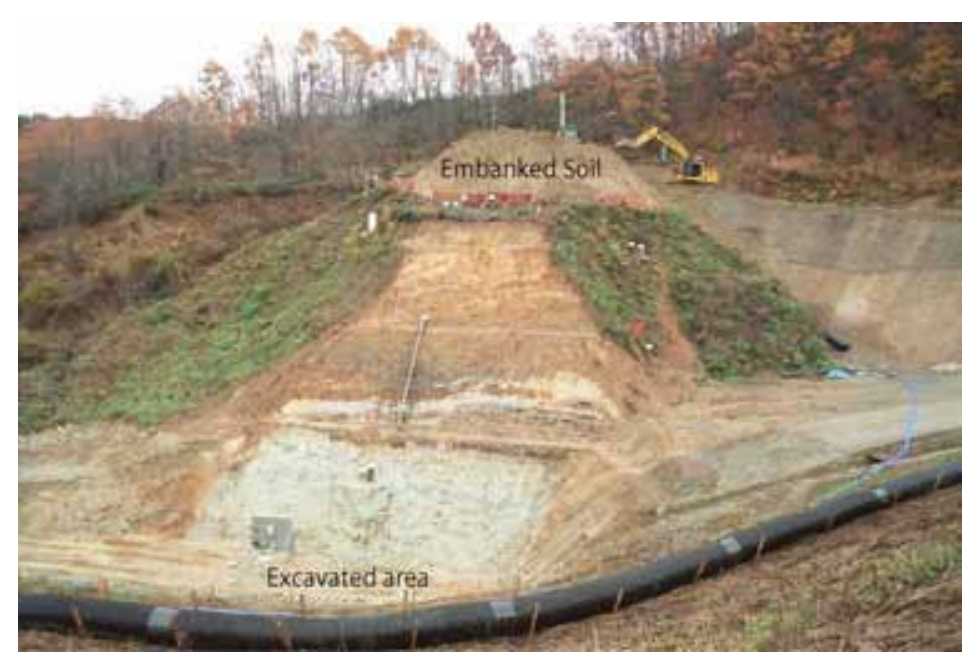

Fig. 2 View of field loading test site, 17 Nov 2000. The soil embankment reached $4.6 \mathrm{~m}$ deep.

(a)

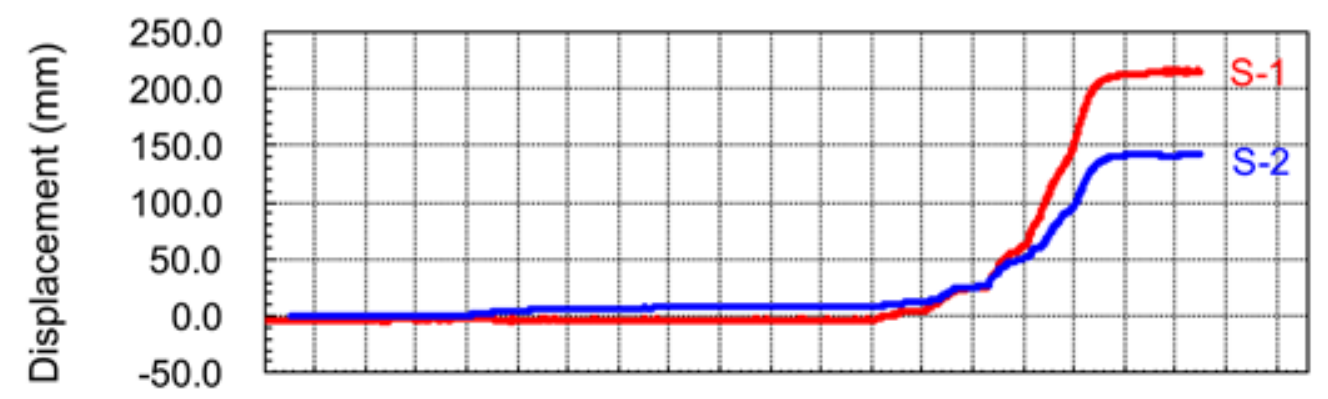

(b)

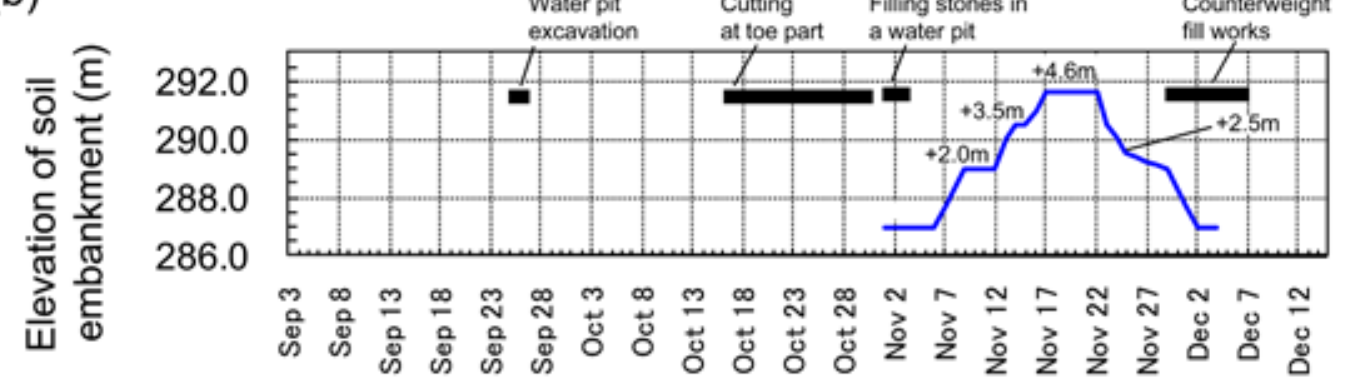

Date in 2000

Fig. 3 Observed displacement of ground extensometers caused by soil embankment. (a)

Observed displacement at S-1 and S-2 between September and December. (b) Changes in embankment height. Blue line, elevation of soil embankment, which is indicated by elevation above sea level. Black bars, periods of other works on the test slope. 


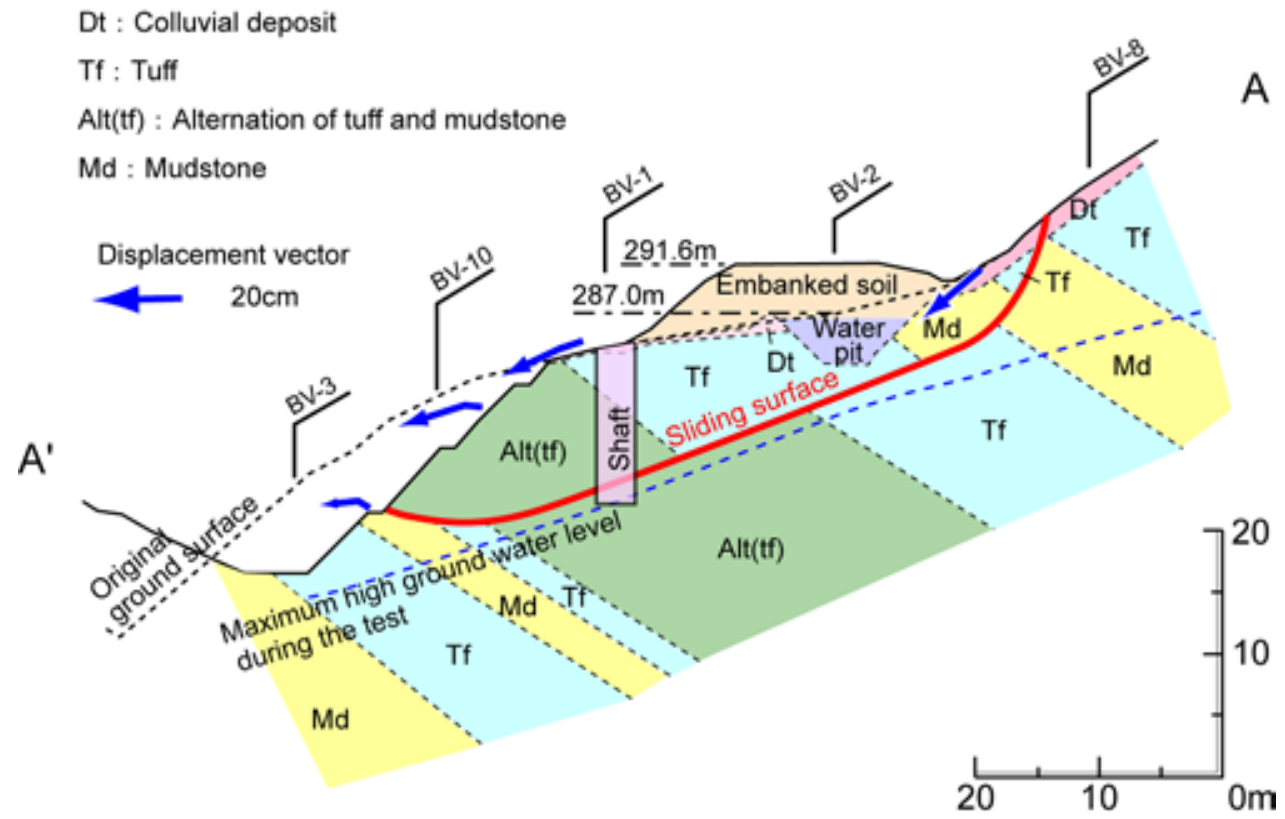

Fig. 4 Section of field loading test site. Dt (pink), colluvial deposit. Tf (sky blue), tuff. Alt(tf) (green), alternation of tuff and mudstone. Md (yellow), mudstone. Red line, sliding surface. Blue area, water pit. Orange area, embankment. Shaded violet area, exploration shaft. Blue arrows, displacement vector from 24 October to 11 December 2000. 
(a)

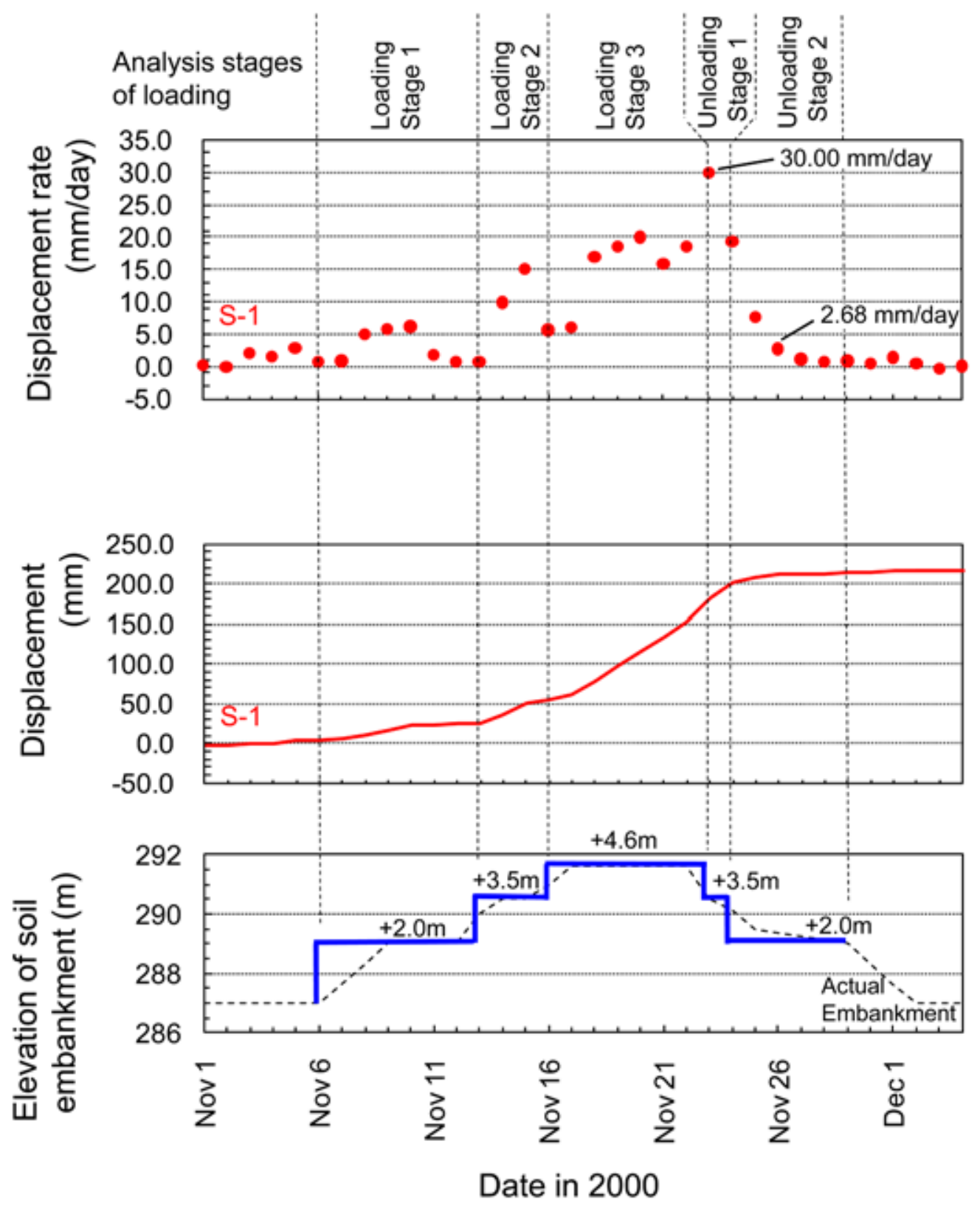

(b)

(c)

Fig. 5 Displacement rate at S-1 and stages of loading used in FEM. (a) Daily displacement rate at S-1. (b) Displacement at S-1. (c) Changes of embankment height. Black broken line, actual elevation of soil embankment; blue line, elevations used in FEM. Embankment height is indicated by elevation above sea level. 
(a)

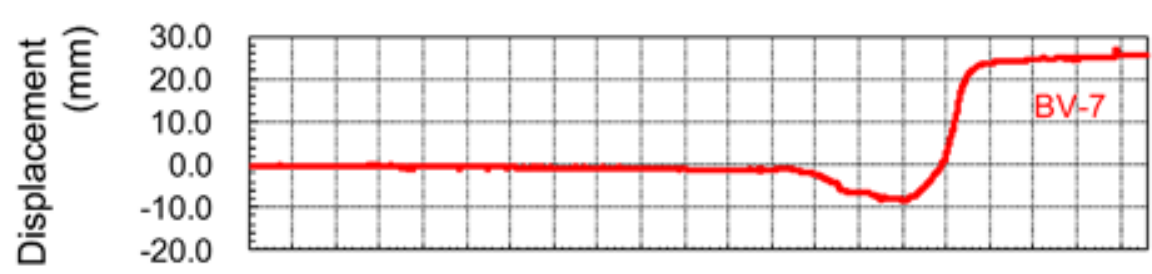

(b)

(c)
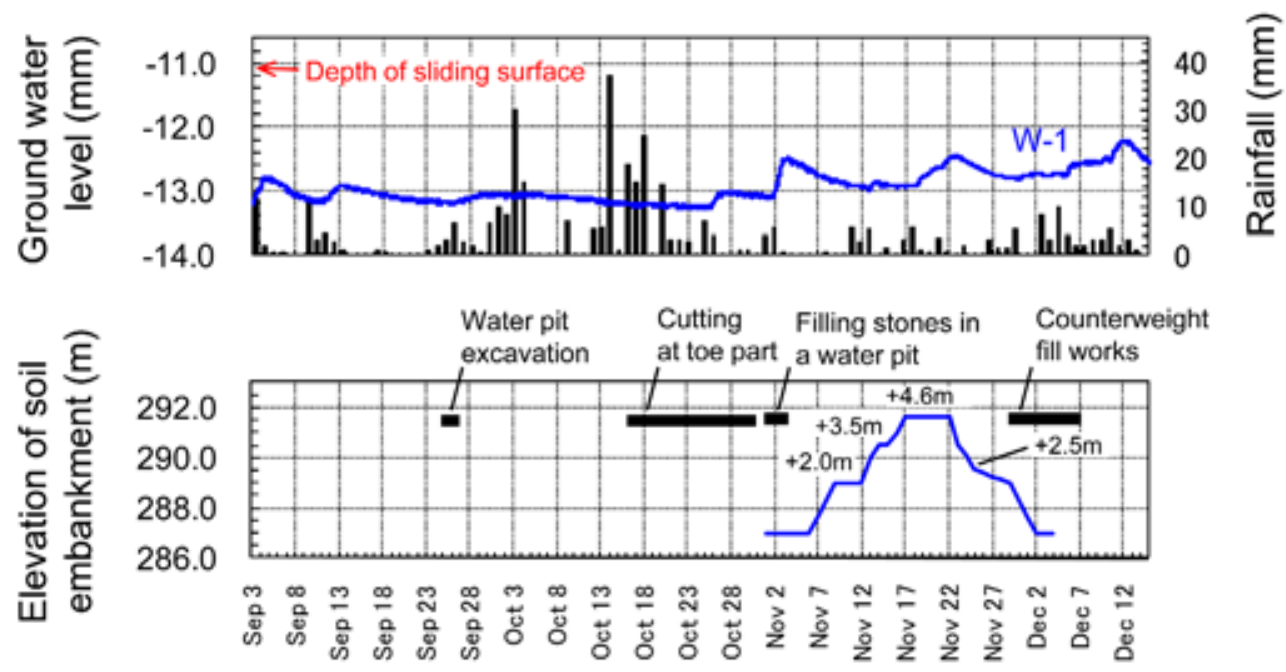

Date in 2000

Fig. 6 Observed vertical displacement and groundwater level. (a) Vertical displacement at BV-7. (b) Ground water level at W-1. (c) Changes in embankment height. Blue line, elevation of soil embankment. Black bars, periods of other works on the test slope. Embankment height is indicated by elevation above sea level. 
(a)

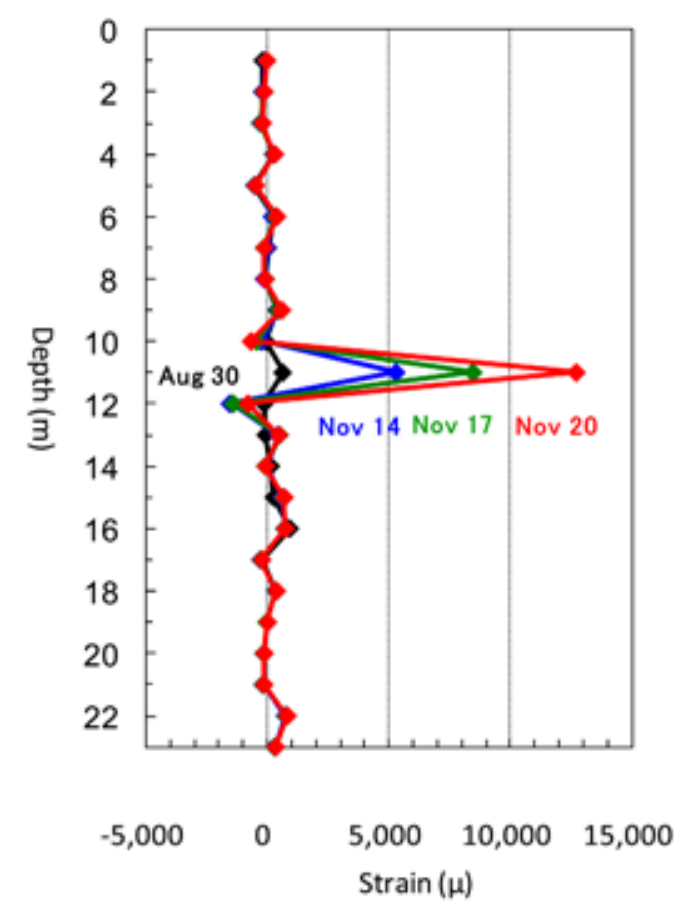

(b)

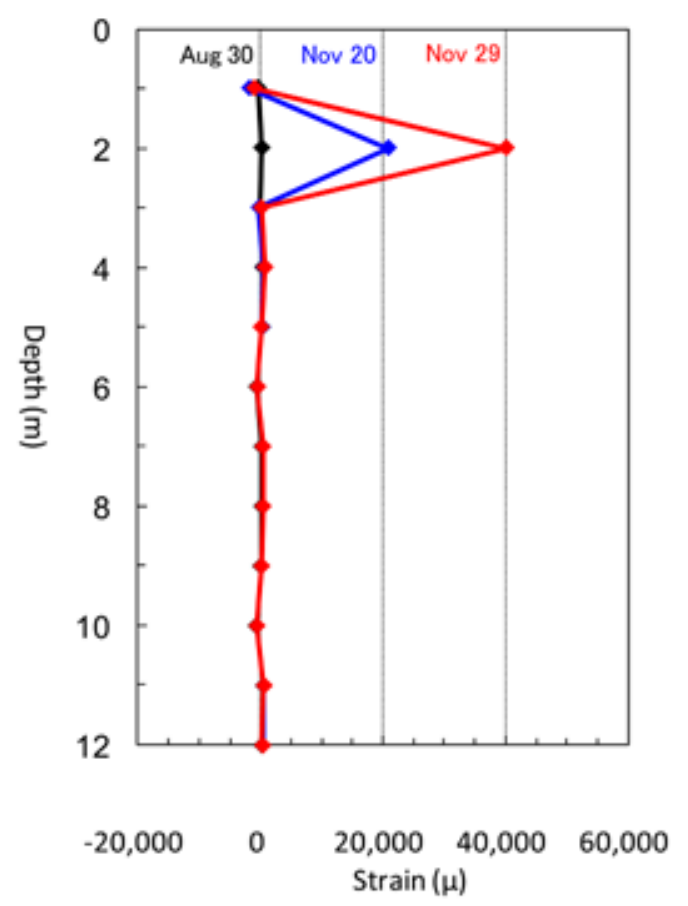

Fig. 7 Strain measurements recorded by pipe strain gauges at W-1 and BV-9. (a) Strain at W1 on indicated dates. (b) Strain at BV-9 on indicated dates. 


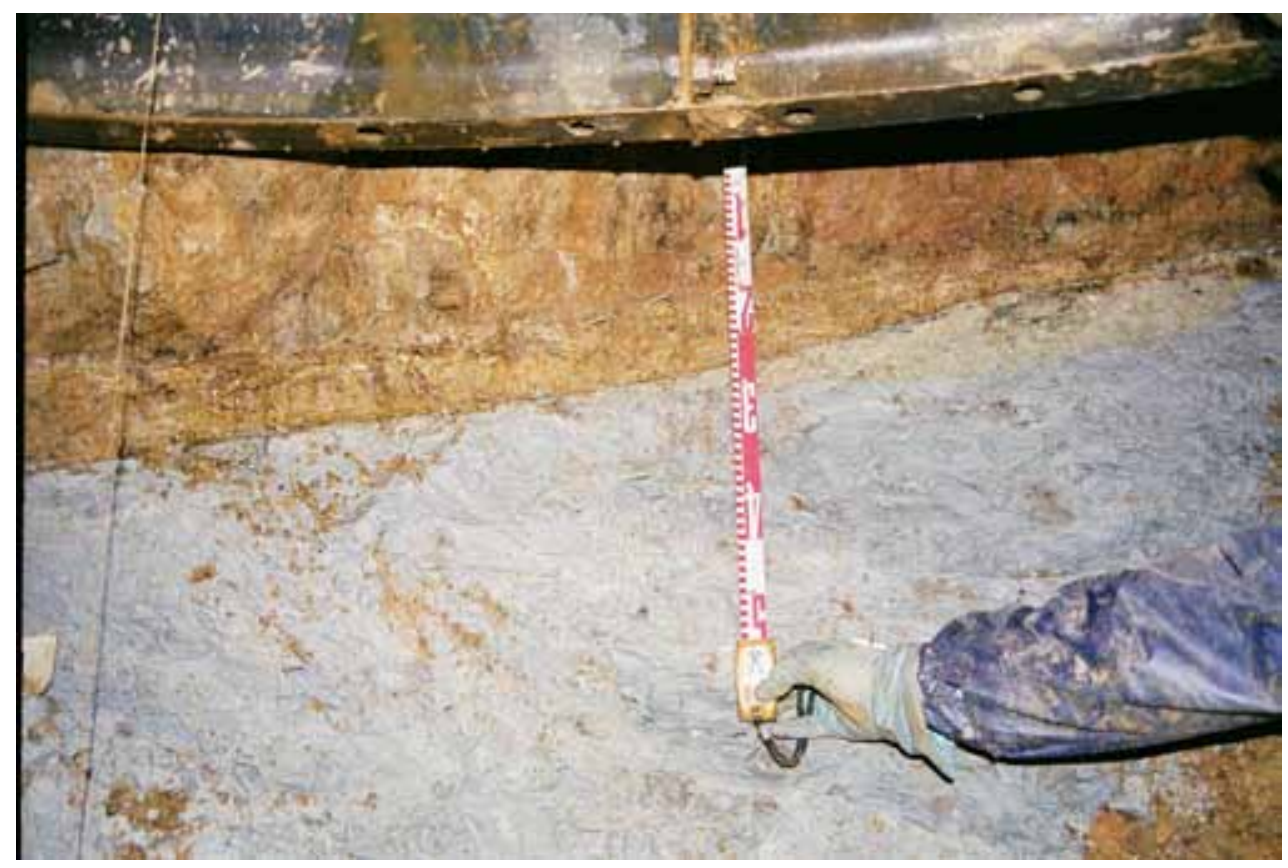

Fig. 8 Sliding surface inside the exploration shaft.

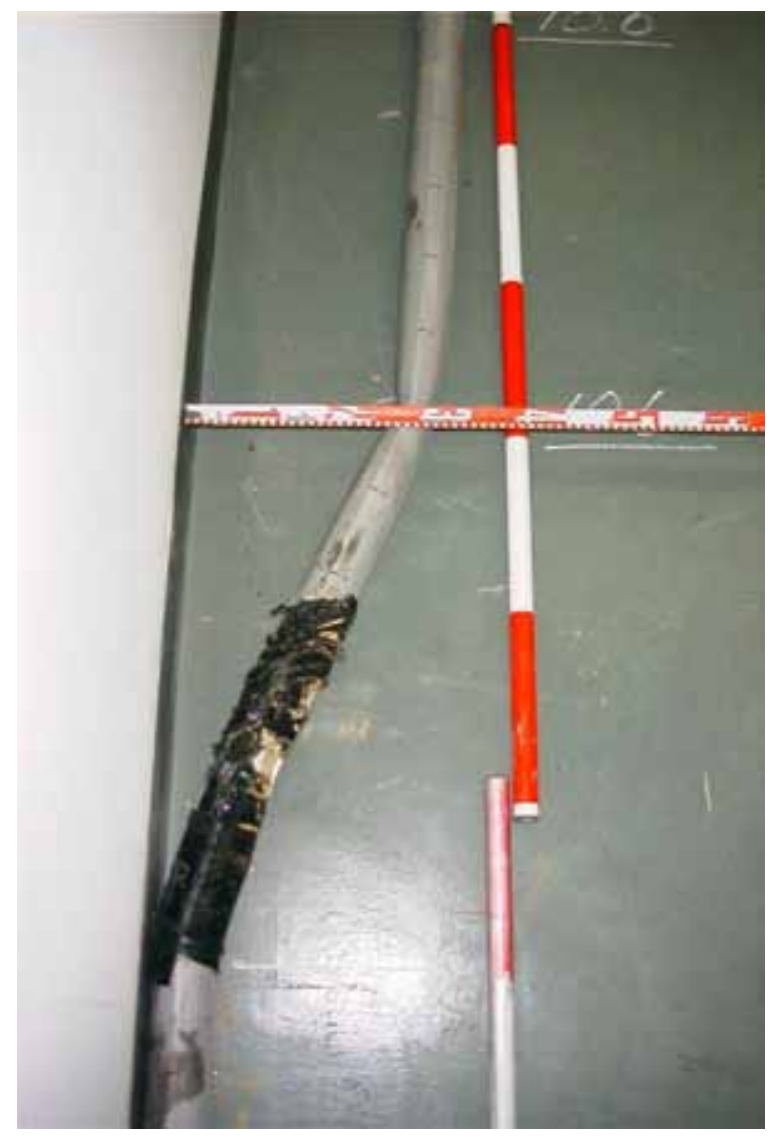

Fig. 9 Bent inclinometer guide pipe retrieved from inside the exploration shaft. 


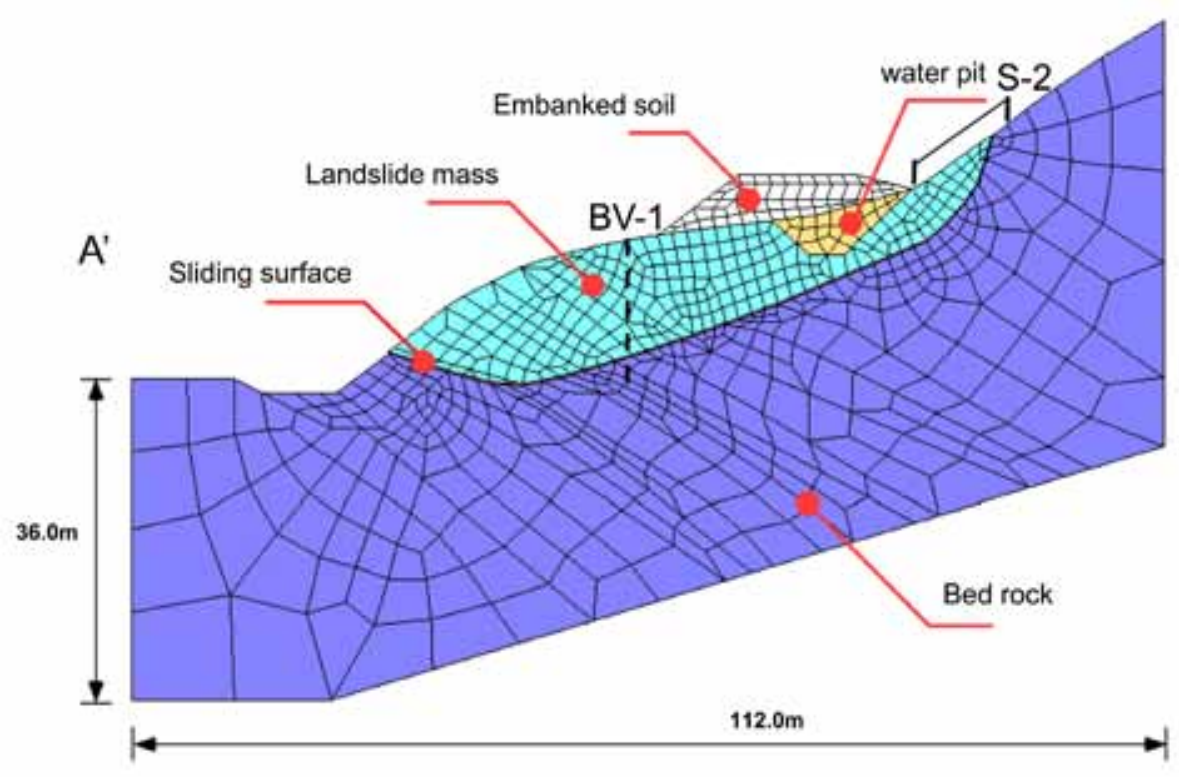

Fig. 10 Finite element model of landslide mass. Landslide mass, bedrock, and embanked soil were modeled as solid elements and assumed elastic body; sliding surface was modeled with joint elements and assumed elasto-viscoplastic body. The properties of a water pit were kept same as those of the landslide mass.

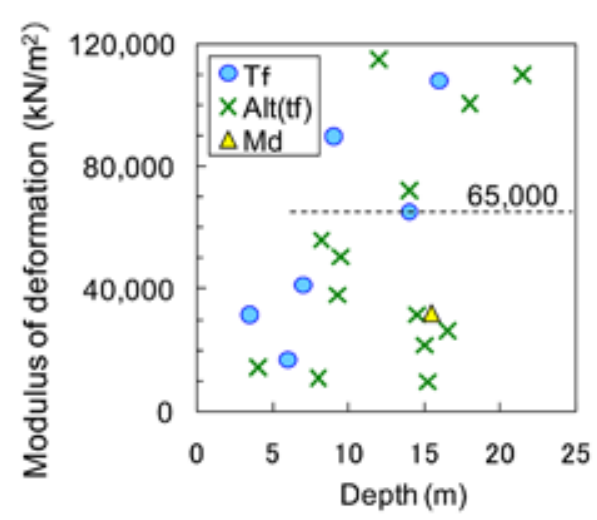

(a) CL class rocks

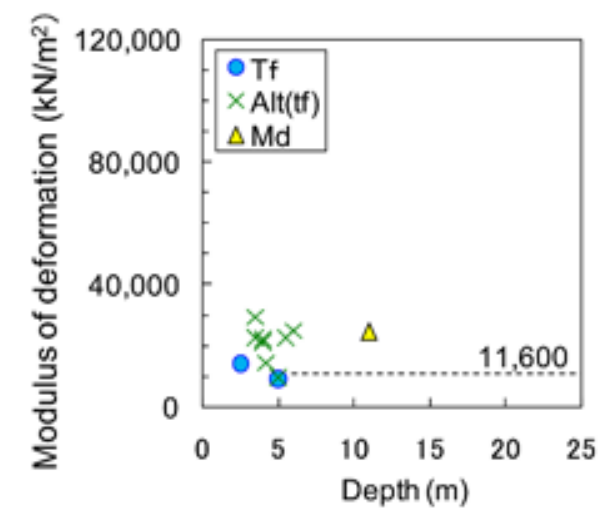

(b) D class rocks

Fig. 11 Modulus of deformation obtained by pressure meter test in borehole. Tf (sky blue circle), tuff. Alt(tf) (green cross), alternation of tuff and mudstone. Md (yellow triangle), mudstone. Classes CL and D rocks classified according to Japanese Geotechnical Society (2004). Dashed lines indicate the mean value of tuff classified as D in (a) and the intermediate value for rock mass in (b). 


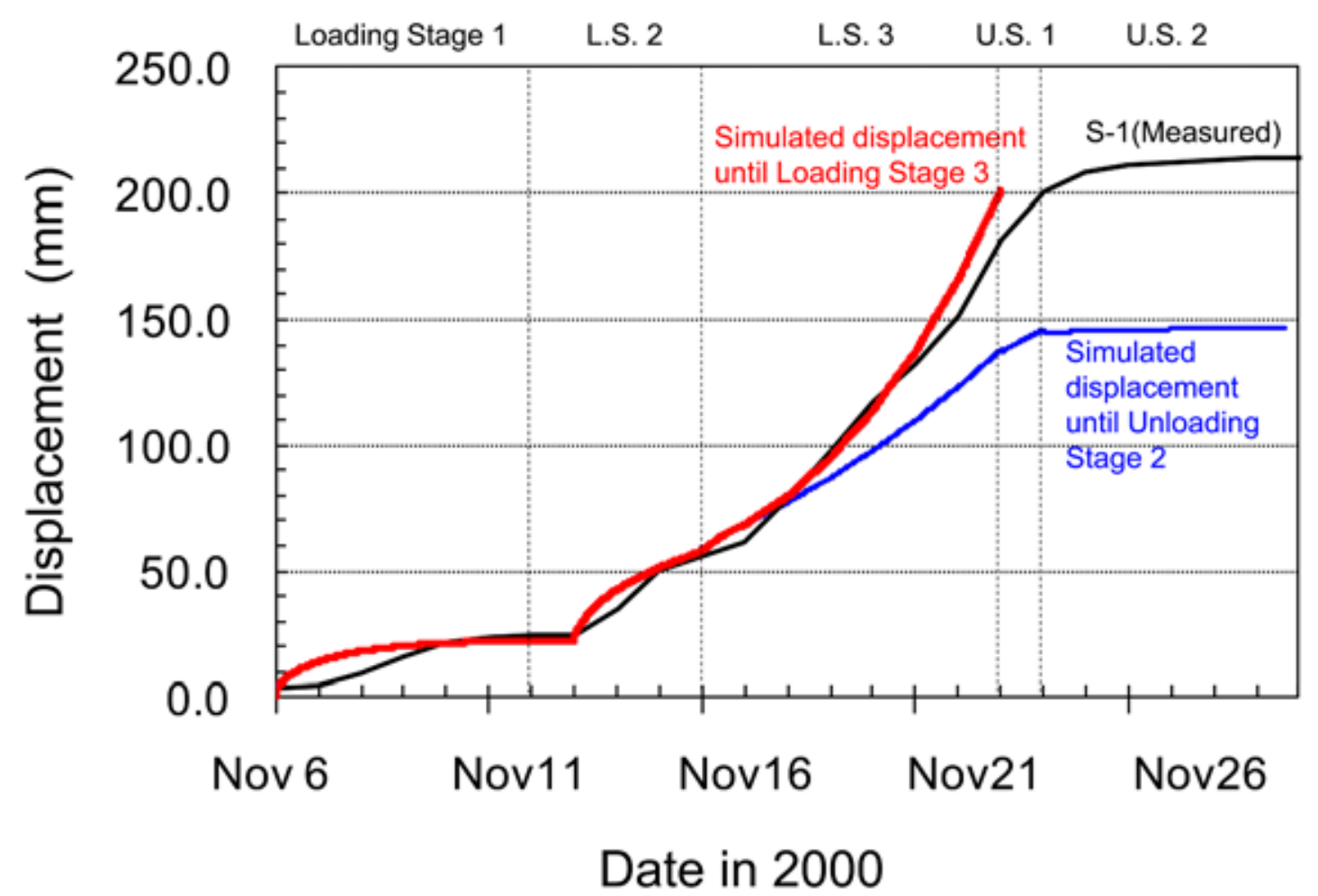

Fig. 12 Simulated and measured ground displacements. Red line, cohesion reduced from 9.1 to $5.0 \mathrm{kN} / \mathrm{m}^{2}$ during loading stage 3. Blue line, cohesion reduced from 9.1 to $7.0 \mathrm{kN} / \mathrm{m}^{2}$ during loading stage 3. Black line, measured displacement at S-1. 
(a)

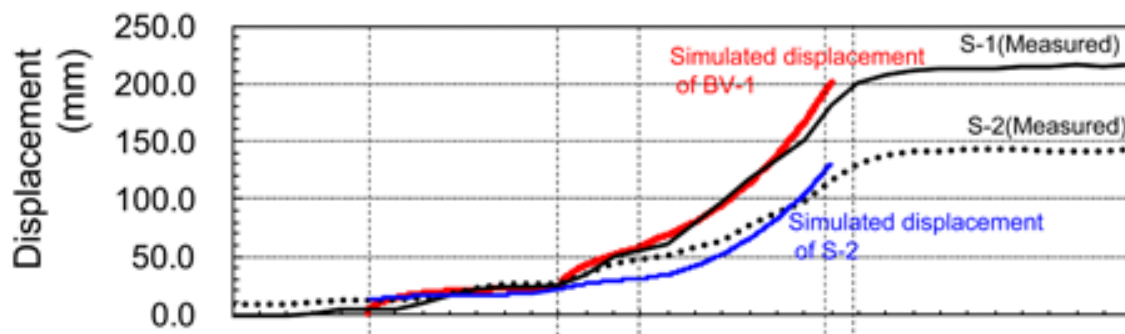

(b)

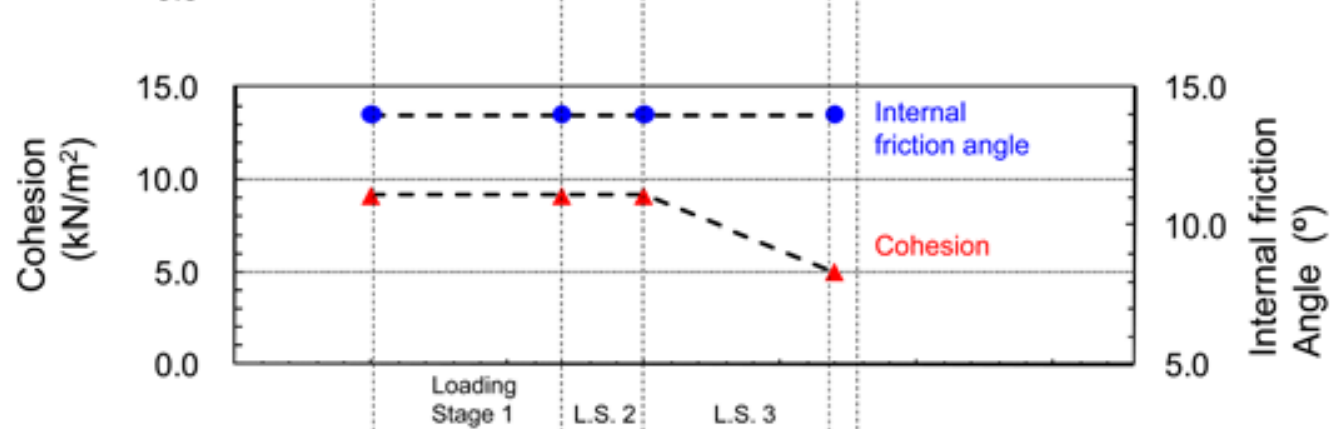

(c)

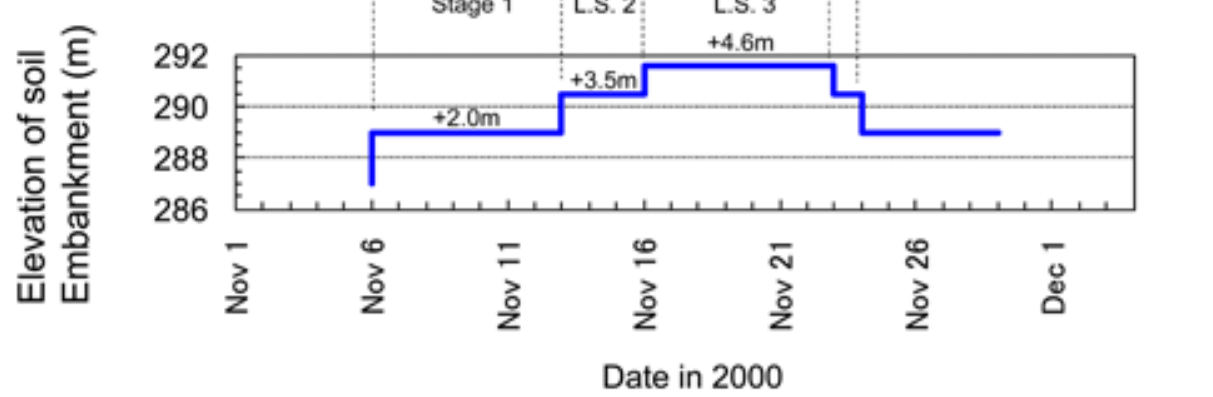

Fig. 13 Analysis result and shear strength parameters. (a) Measured and simulated displacements at S-1 and S-2. (b) Back-calculated shear strength parameters of the sliding surface. (c) Changes in embankment height during the analysis stages. Embankment height is indicated by elevation above sea level. 
(a)

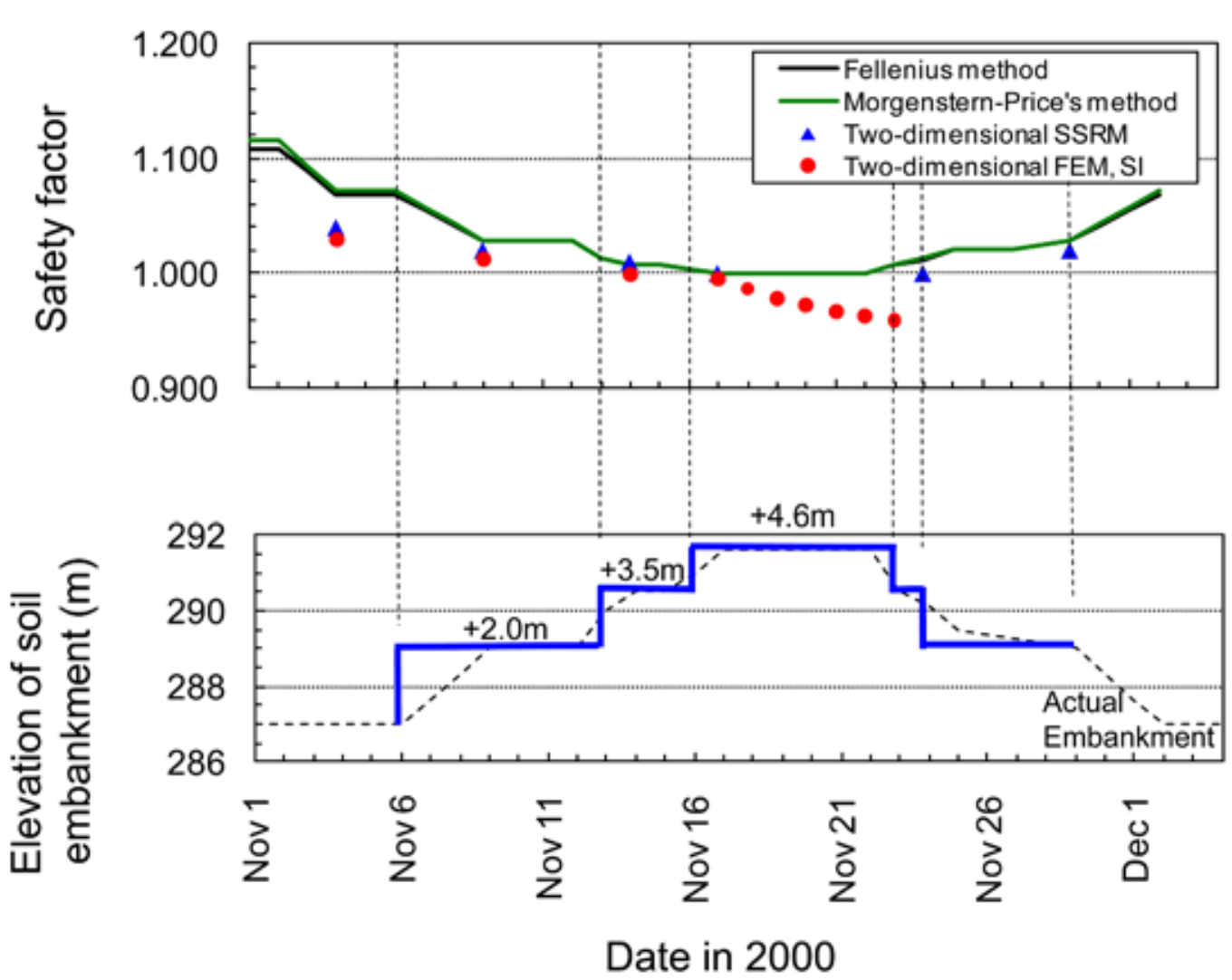

Fig. 14 Comparison of safety factors obtained by different methods. (a) Calculated safety factors. (b) Changes in embankment height during the analysis stages. Embankment height is indicated by elevation above sea level. 
(a)

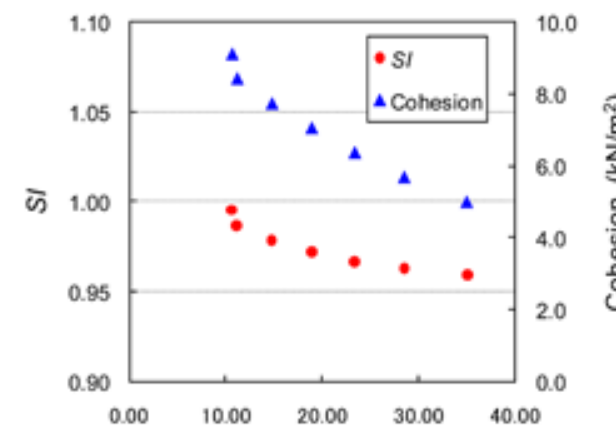

Simulated displacement rate of BV-1 (mm/day) (b)

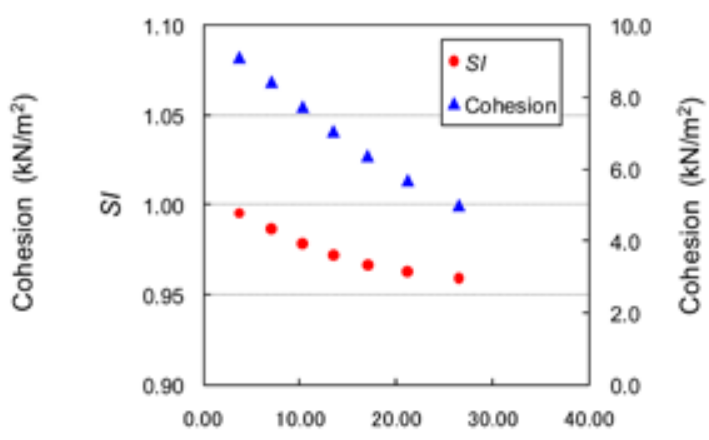

Simulated displacement rate of S-2 ( $\mathrm{mm} /$ day)

Fig. 15 Correlations of simulated displacement rates with strengths of sliding surface and SI at loading stage 3 at (a) BV-1 and (b) S-2.

(a)

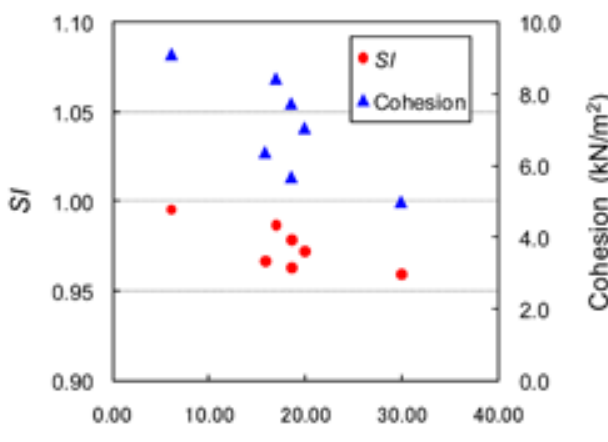

Measured displacement rate of S-1 (mm/day) (b)

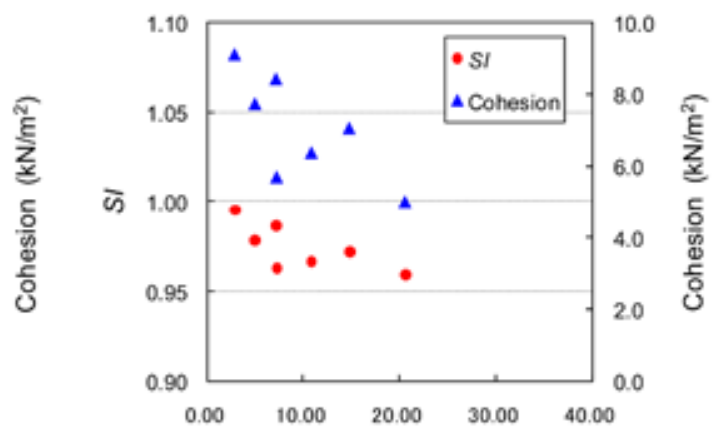

Measured displacement rate of S-2 ( $\mathrm{mm} /$ day)

Fig. 16 Correlations of measured displacement rates with strengths of sliding surface and SI at loading stage 3 at (a) S-1 and (b) S-2. 